\title{
UTILIDAD DE LA ENTEROCLISIS POR TOMOGRAFIA COMPUTADA (E-TC) EN LA DETECCION DE TUMORES DE INTESTINO DELGADO
}

\author{
Drs. Cecilia Besa C ${ }^{(1)}$, Andrés O' Brien $\mathbf{S}^{(2)}$, Juan Pablo Cruz $Q^{(1)}$.
}

1. Residente de Radiología, Departamento de Radiología. Hospital Clínico Pontificia Universidad Católica de Chile.

2. Departamento de Radiología, Hospital Clínico Pontificia Universidad Católica de Chile.

\section{USEFULNESS OF THE MULTIDETECTOR COMPUTED TOMOGRAPHY ENTEROCLYSIS (MDCT-E) IN THE DETECTION OF SMALL BOWEL NEOPLASMS}

\begin{abstract}
Small bowel neoplasms are rare, accounting for approximately 3-6\% of all primary malignancies of the gastrointestinal tract. MDCT-E is an imaging modality that combines the advantages of enteroclysis and helical CT, allowing the detection of small bowel diseases wherever they are located (intraluminal, intramural, or extramural). The aim of our study was to assess the reliability of MDCT-E in the detection of small bowel neoplasms. In our institution, MDCT-E was used to study 600 patients admitted for suspicion of small bowel diseases, between January 2005 and May 2008. A total of 22 (3, $6 \%$ ) small bowel neoplasms were identified, all confirmed by histological examination. The neoplasms found in this series were adenocarcinoma (n: 4), lymphoma ( $($ : 3), carcinoid tumor (n: 3), benign GIST (n: 2), benign hamartomatous polyps ( $n$ : 2) and secondary small bowel tumors ( $n: 8)$. MDCT-E appears to be a reliable method in the detection of small bowel neoplasms, allowing tumor staging to be determined during the same procedure.

Keywords: Computed tomography, Enteroclysis, Intestine, Multidetector row, Small bowel neoplasms.
\end{abstract}

Resumen: Los tumores de intestino delgado (ID) son raros, representando aproximadamente 3-6\% de las neoplasias del tubo digestivo. La E-TC es una técnica que combina las ventajas de la enteroclisis con las

Besa C. y cols. Utilidad de la enteroclisis por tomografía computada (E-TC) en la detección de tumores de intestino delgado. Rev Chil Radiol 2008; 14: 211-218.

Correspondencia: Dra. Cecilia Besa $C$.

besacecilia@gmail.com

Trabajo recibido el 22 de septiembre de 2008, aceptado para publicación el 11 de noviembre de 2008. de la TC multicorte, con el potencial de demostrar alteraciones intraluminales, murales y extraintestinales. El objetivo de nuestro estudio fue evaluar el potencial diagnóstico de la E-TC en la detección de tumores de ID. En nuestra institución se realizaron 600 E-TC desde Enero del 2005 a Mayo del 2008. Un total de 22 pacientes (3,6\%) presentaron hallazgos tomográficos compatibles con tumores de ID, todos confirmados histológicamente. Los tumores encontrados en esta serie fueron; adenocarcinoma ( $n: 4)$, linfoma ( $n: 3)$, tumor carcinoide (n:3), tumor estromal gastrointestinal benigno (n:2), pólipos hamartomatosos (n:2) y compromiso neoplásico secundario (n:8). Esta serie corrobora el valor de la E-TC como técnica de imagen de elección en la detección de tumores de ID, con la posibilidad de etapificación en el mismo procedimiento.

Palabras clave: Enteroclisis, Tomografía computada multidetector, Tumores de intestino delgado, Intestino.

\section{Introducción}

Los tumores de intestino delgado (ID) son raros, representando aproximadamente $3-6 \%$ de las neoplasias del tubo digestivo; en pacientes sintomáticos hasta un $60 \%$ de los casos son malignos ${ }^{(1,2)}$. Generalmente tienen una presentación clínica inespecífica, similar a otros procesos que afectan al tracto gastrointestinal, por lo que su diagnóstico es tardío y difícil. En la mayoría de los casos son asintomáticos hasta etapas avanzadas de la enfermedad. Cuando presentan síntomas, los más comunes son: dolor abdominal, pérdida de peso, naúseas, vómitos, diarrea, hemorragia digestiva y obstrucción intestinal, que en general se relacionan con el tamaño tumoral y localización en el ID ${ }^{(3)}$.

Los tumores benignos y malignos del ID pueden tener origen en todos los componentes histológicos que forman el intestino incluyendo: tejido epitelial, tejido linfoide, vasos, nervios y músculo(4). 
Los tumores malignos más frecuentes son el adenocarcinoma, tumor carcinoide, linfoma y tumor estromal gastrointestinal maligno en orden de frecuencia, siendo el duodeno la ubicación mas común del adenocarcinoma y el apéndice e ileon del tumor carcinoide gastrointestinal. Estos en general se presentan con compromiso metastásico al momento del diagnóstico, factor responsable del mal pronóstico de estas lesiones ${ }^{(2,4-7)}$. La enfermedad de Crohn se asocia a un mayor riesgo de desarrollar tumores malignos de ID -adenocarcinoma- afectación que es frecuentemente multifocal y de predominio en el ileon distal. Otras condiciones que predisponen a mayor riesgo de neoplasias malignas de ID son: enfermedad celíaca, síndrome familiar de pólipos adenomatosos, neurofibromatosis y síndrome de Peutz-Jeghers, entre otros.

La mayoría de los tumores benignos de ID son asintomáticos y diagnosticados en forma incidental, siendo los más comunes: adenoma, tumores estromales gastrointestinales benignos, leiomioma, lipoma, hemangiomas y pólipos, estos últimos pueden ser secundarios a un síndrome de Peutz-Jeghers, enfermedad que se caracteriza por pigmentación mucocutánea y múltiples pólipos hamartomatosos en todo el tracto gastrointestinal, de predominio en el ID ${ }^{(1,2,4-7)}$.

Existen diversos métodos para la evaluación del ID, que incluyen estudios baritados, tomografía computada (TC), resonancia magnética (RM), enteroscopía y la cápsula endoscópica. El tránsito o "radiografía de intestino delgado", consiste en la administración oral de contraste baritado con observación fluoroscópica y obtención de varias radiografías del abdomen a medida que el contraste avanza por el intestino. Por años, esta técnica ha sido el método de elección en la evaluación de patología de ID. Sin embargo, las desventajas intrínsecas del método: bajo valor predictivo negativo, operador dependiente, visualización indirecta de la pared y falta de visualización del compromiso extraintestinal entre otras, la han desplazado como técnica diagnóstica ${ }^{(8,9)}$.

La enteroclisis por tomografía computada (E-TC) es hoy en día el método de imágenes de elección en el estudio de patología tumoral y no tumoral de ID $^{(10-12)}$. Esta técnica combina las ventajas de la enteroclisis tradicional (adecuada distensión de asas intestinales) con las de la TC multicorte, con el potencial de demostrar en forma simultánea alteraciones intraluminales, murales y extraintestinales. La E-TC consiste en la realización de una TC de abdomen y pelvis (con técnica multidetector) con contraste endovenoso en fase arterial y portovenosa, posterior a la administración de agua a temperatura ambiente a través de una sonda nasoenteral colocada bajo fluoroscopía en el ángulo de Treitz, procedimiento que es bien tolerado en la mayoría de los pacientes.

\section{Objetivos}

Los objetivos del presente estudio son:

- Describir la utilidad y potencial diagnóstico de la E-TC en la detección y evaluación de tumores benignos y malignos de ID.

- Describir las características tomográficas de los diferentes tumores de ID confirmados histológicamente en nuestra serie de pacientes.

\section{Materiales y métodos}

Durante el período comprendido entre enero del 2005 y mayo del 2008 se realizaron 600 E-TC consecutivas en nuestra institución, por sospecha de patología de intestino delgado. Las principales indicaciones clínicas fueron: sospecha de enfermedad inflamatoria intestinal o tumores intestinales, hemorragia gastrointestinal de etiología desconocida, obstrucción intestinal y dolor abdominal persistente.

La técnica utilizada para E-TC en nuestra institución consiste en ${ }^{(8)}$ :

- Procedimiento realizado en forma ambulatoria $u$ hospitalaria.

- Ayuno de 6 a 8 horas.

- Instalación de sonda nasoenteral (Kangaroo 8F) en sala de fluoroscopía, que idealmente debe quedar en el ángulo de Treitz.

- Administración de 2 litros de agua en 10-15 minutos, según tolerancia, en la sala de TC. En caso de no poder instalar la sonda se da a beber agua por vía oral.

- $\quad$ Administración de 10 mg de buscapina ${ }^{\circledR}$ por vía endovenosa.

- Realización de TC de abdomen y pelvis posterior a la administración de 100-120 cc de contraste endovenoso no iónico (Omnipaque $300^{\circledR}$ ) a 3-4 cc/seg.

- $\quad$ Adquisición de imágenes en fase arterial, 25-30 segundos post-contraste y en fase porto-venosa, 70 segundos post-contraste, en tomógrafos de 8 y 64 detectores.

- El post-proceso de imágenes se realiza con reconstrucción de imágenes de $1,2 \mathrm{~mm}$ de grosor y multiplanares o 3D en estaciones de trabajo.

En forma retrospectiva se analizaron los resultados de las 600 E-TC, en busca de hallazgos tomográficos compatibles con patología tumoral de ID. Los estudios fueron considerados positivos para patología tumoral en los siguientes casos:

- $\quad$ Engrosamiento parietal focal de asa de ID (> 3 $\mathrm{mm}$ ) de aspecto tumoral (simétrico-asimétrico, circunferencial-excéntrico).

- Estenosis tumoral de ID; lumen intestinal reducido, con dilatación proximal de asas.

- Masa de ID (plana, sésil, polipoídea) identificada 
en al menos dos planos y distinguible de pliegues intestinales.

- Compromiso de ID secundario a tumor extraintestinal o carcinomatosis peritoneal.

Se evaluó también la presencia de masas del mesenterio, adenopatías y compromiso tumoral de órganos distantes.

\section{Resultados}

La E-TC detectó hallazgos consistentes con tumores de intestino delgado en 25 pacientes. Tres pacientes fueron excluidos del estudio por no tener confirmación anatomopatológica, por lo que se analizaron 22 pacientes $(3,6 \%)$ con tumores de ID confirmados histológicamente. La edad promedio de los pacientes estudiados fue de 56 años, con $54.5 \%$ (n:12) de mujeres y $45 \%$ (n:10) de hombres.

En tres pacientes no fue posible instalar una sonda nasoenteral y el agua fue administrada vía oral, sin embargo el examen fue técnicamente satisfactorio con adecuada distensión de asas de ID en todos los casos analizados. El procedimiento fue bien tolerado, sin documentarse efectos adversos secundarios al uso de contraste yodado endovenoso.

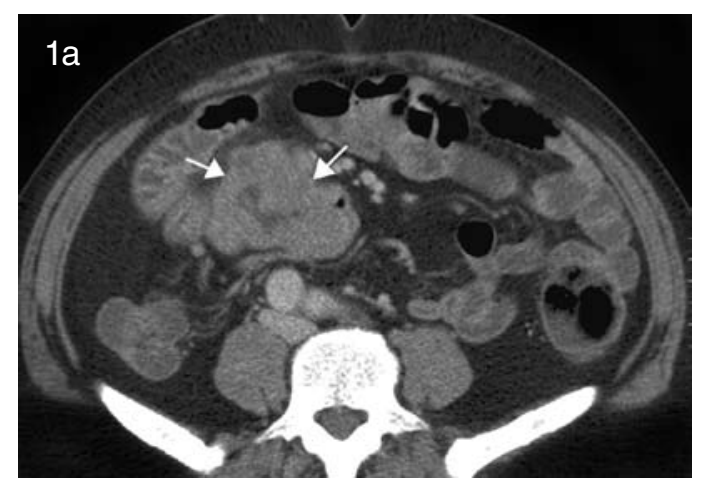

Figura 1. Hombre de 59 años con adenocarcinoma de yeyuno. a) E-TC axial: masa transmural infiltrante de yeyuno proximal, con compromiso del tejido adiposo mesentérico (flechas). b) Reconstrucción coronal: fístula entero-entérica entre el asa de yeyuno comprometida y asa de ileon distal (flechas).
En esta serie de tumores, los diagnósticos fueron: adenocarcinoma (n:4), linfoma (n:3), tumor carcinoide ( $\mathrm{n}: 3)$, tumor estromal gastrointestinal benigno (GIST) $(\mathrm{n}: 2)$, pólipos hamartomatosos (Sd. Peutz Jeghers) $(\mathrm{n}: 2)$, compromiso tumoral secundario de ID por compromiso metastático (n:6), tumor desmoide (n:1) y sarcoma (n:1).

En todos los casos el diagnóstico se realizó mediante el análisis de las series de imágenes axiales, sin embargo las reconstrucciones multiplanares (coronales y sagitales) fueron útiles para una mejor caracterización del tamaño y morfología del tumor y para una definición más precisa de la relación de la lesión tumoral con las estructuras anatómicas vecinas.

Los tumores malignos constituyeron la mayoría de los casos de nuestra serie $(81 \%)$, siendo los tumores primarios de ID los más frecuentes. El adenocarcinoma (n:4, 18\%) fue la etiología más común; 3 de éstos comprometían asas de yeyuno proximal y se presentaron como engrosamiento parietal concéntrico, estenosante y con formación de fístula entero-entérica en un caso (Figuras 1, 2). El tumor restante se localizaba en el ileon proximal y presentaba morfología polipoídea con engrosamiento parietal adyacente (Figura 3).
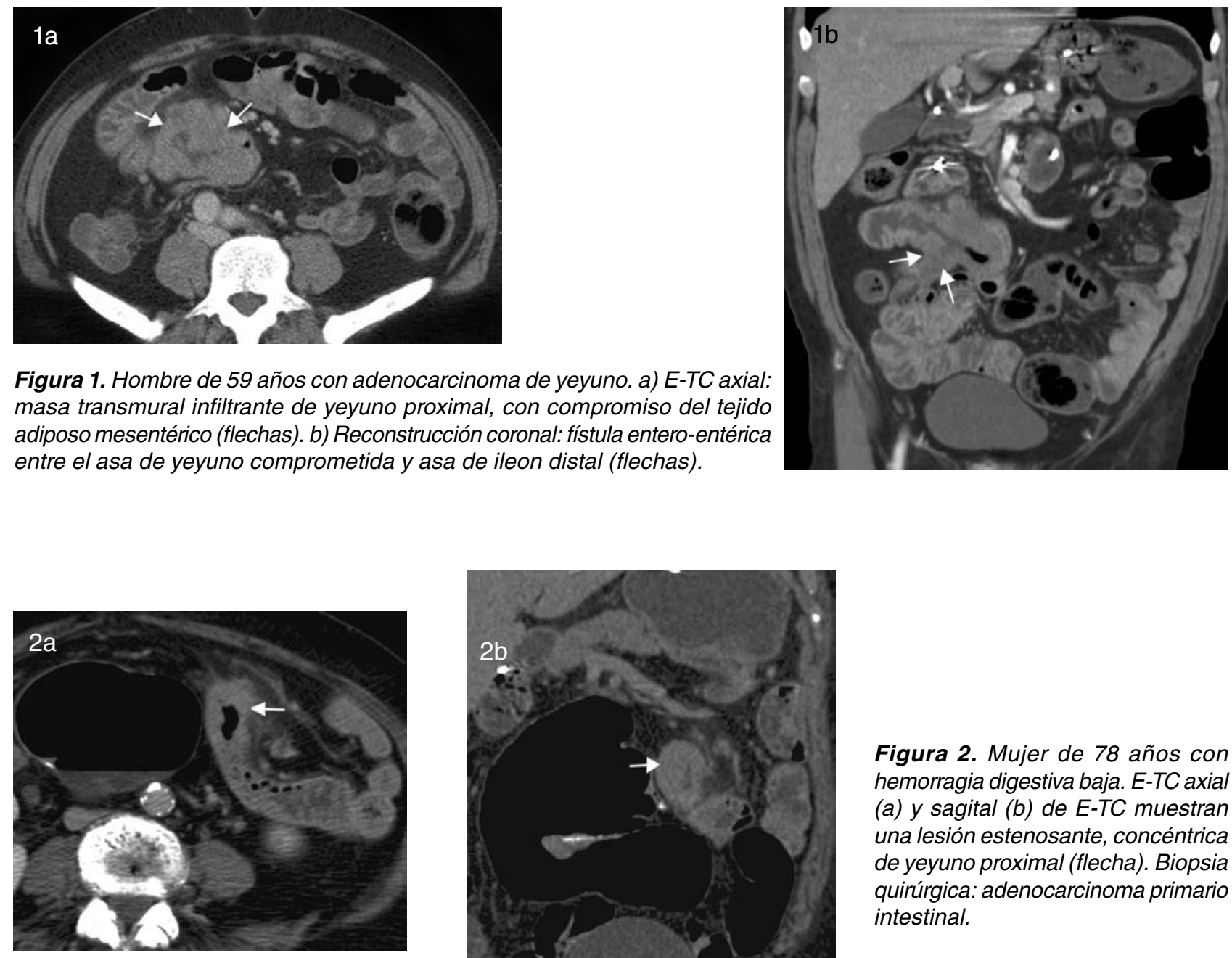

Figura 2. Mujer de 78 años con hemorragia digestiva baja. E-TC axial (a) y sagital (b) de E-TC muestran una lesión estenosante, concéntrica de yeyuno proximal (flecha). Biopsia quirúrgica: adenocarcinoma primario intestinal. 
Figura 3. Mujer de 68 años con adenocarcinoma de yeyuno. E-TC Imágenes axial y sagital $(a, b)$ muestran lesión focal estenosante en asa de yeyuno proximal que se refuerza con medio de contraste e.v., compatible con adenocarcinoma (flechas) y edema parietal del asa proximal, "intestino de lucha" (cabeza de flecha).
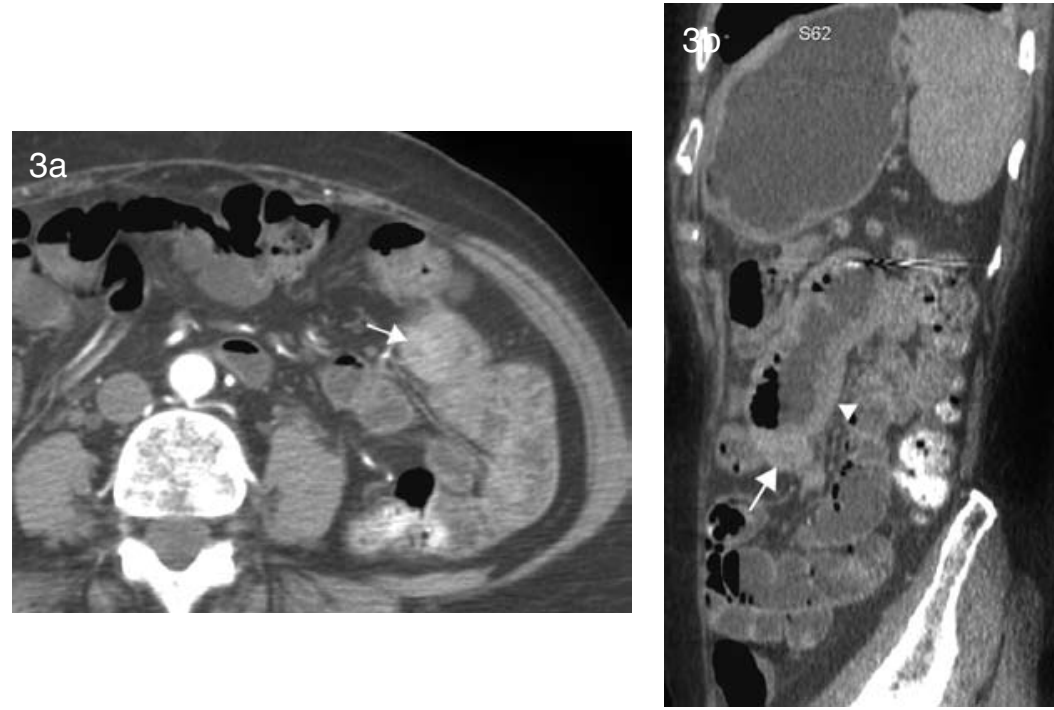

Los tres tumores carcinoides (14\%) detectados mediante E-TC comprometían asas de ileon medio y distal, en 2 casos multifocales. Estos tumores fueron visualizados como lesiones nodulares parietales, hipervasculares, de 5 a 20 $\mathrm{mm}$ de diámetro mayor, asociadas a adenopatías mesentéricas de contornos espiculados (Figura 4). Un paciente presentó compromiso metastásico hepático (Figura 5).

Tres pacientes (14\%) presentaron compromiso de intestino delgado por linfoma. En 2 casos, el compromiso intestinal se manifestó como un engrosamiento parietal circunferencial no estenosante y en un caso como una lesión parietal sólida excéntrica (Figura 6 ); todos los casos se asociaron a conglomerado nodal mesentérico. Un paciente presentó compromiso asociado del colon ascendente y ciego por linfoma (Figura 7).
Los casos de compromiso tumoral secundario de ID $(36 \%)$ fueron por: carcinomatosis peritoneal $(n: 4)$, localización secundaria intraintestinal (n:1) (Figura 8), infiltración duodenal por adenocarcinoma pancreático (n:1) (Figura 9), sarcoma con infiltración de asa de ileon $(n: 1)$ y gran tumor desmoide con compromiso de asa de ileon (n:1).

En cuanto a los tumores benignos primarios detectados mediante E-TC, se diagnosticaron 2 casos de tumores estromales gastrointestinales benignos (GIST) (9\%) los que se presentaron como un tumor submucoso duodenal (Figura 10) y como masa sólida, exofítica, con área de ulceración en asa de ileon (Figura 11). Se detectaron 2 casos (9\%) de Síndrome de Peutz-Jeghers, que se presentaron como múltiples lesiones polipoídeas intraluminales en intestino delgado con compromiso gástrico y colónico en 1 caso (Figuras 12, 13).
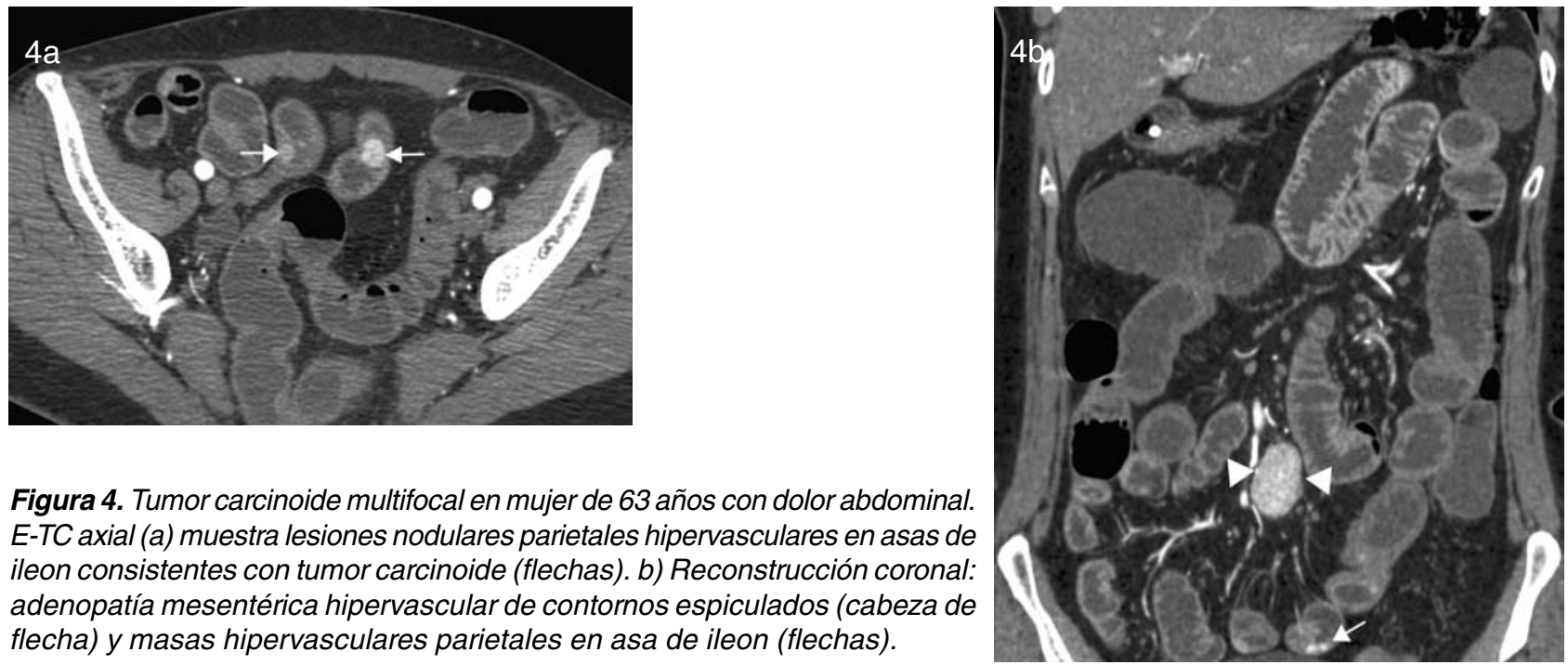

Figura 4. Tumor carcinoide multifocal en mujer de 63 años con dolor abdominal. E-TC axial (a) muestra lesiones nodulares parietales hipervasculares en asas de ileon consistentes con tumor carcinoide (flechas). b) Reconstrucción coronal: adenopatía mesentérica hipervascular de contornos espiculados (cabeza de flecha) y masas hipervasculares parietales en asa de ileon (flechas). 

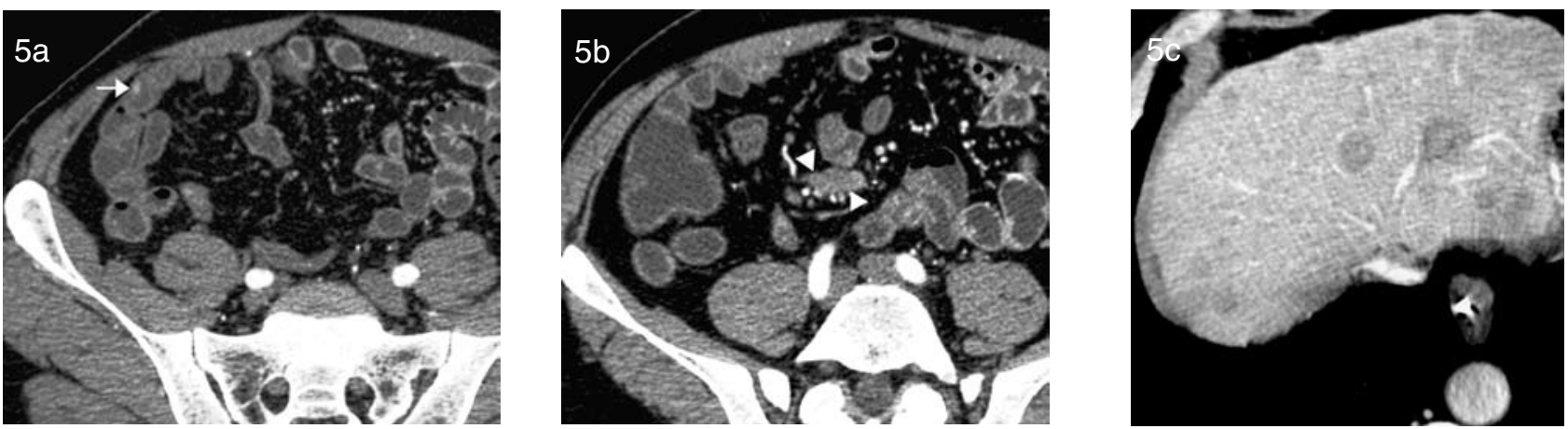

Figura 5. Hombre de 62 años con carcinoide metastático. a, b) E-TC axial: lesión nodular hipervascular de 5 mm en asa de ileon medio y conglomerado de adenopatías a nivel mesentérico. c) Hígado con múltiples lesiones metastásicas hipovasculares.
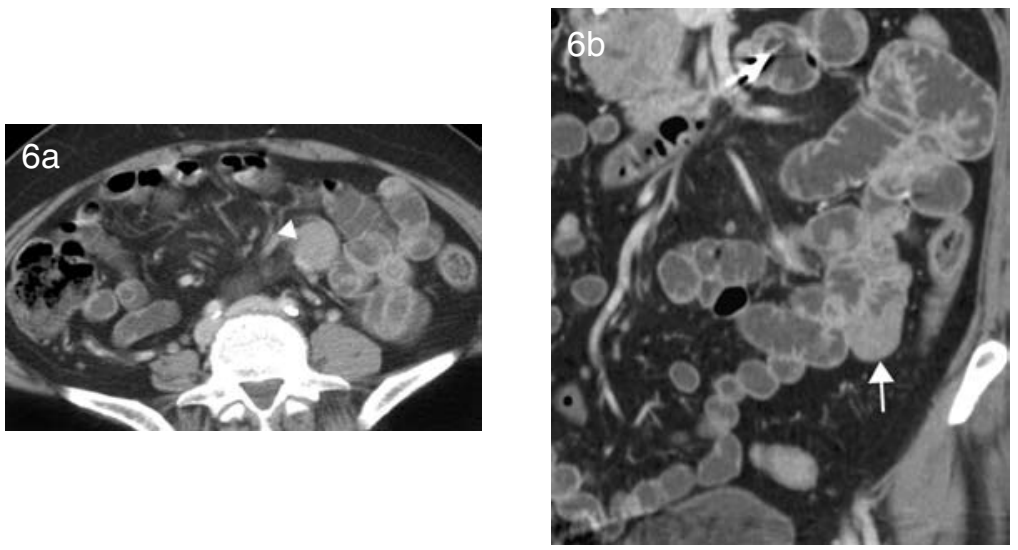

Figura 6. Mujer de 61 años con linfoma no Hodgkin de yeyuno distal. E-TC: (a) Imagen axial, masa mesentérica (cabeza de flecha) y múltiples pequeños linfonodos adyacentes asociados. (b) coronal, lesión parietal sólida, exoentérica con refuerzo homogéneo con el uso de contraste e.v en asa de yeyuno (flecha).
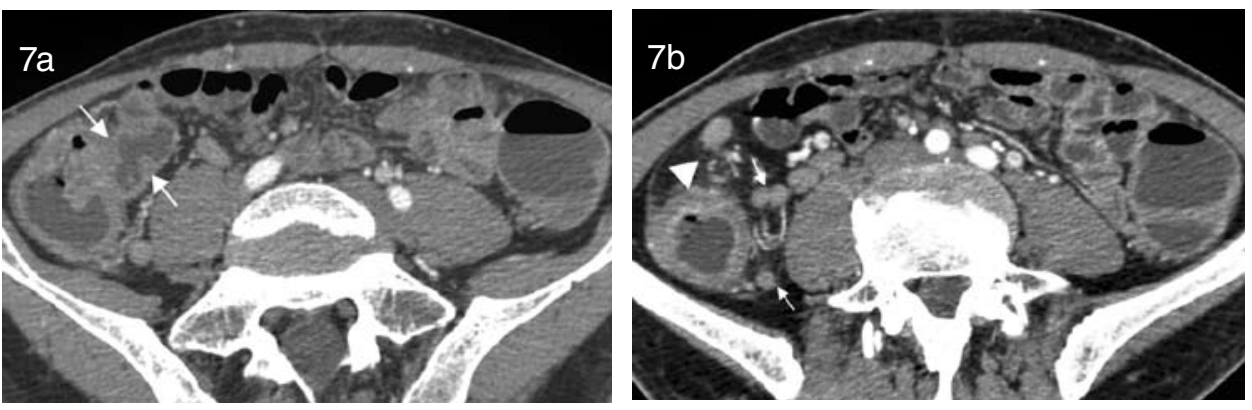

Figura 7. Hombre de 52 años con dolor abdominal y pérdida de peso. $a, b)$ Imágenes axiales de E-TC: leve engrosamiento parietal de ileon terminal (flechas) y significativo engrosamiento del ciego y colon ascendente (cabeza de flecha), asociados a múltiples adenopatías mesentéricas ileocólicas (flechas). Estudio histológico: linfoma intestinal de células $T$.
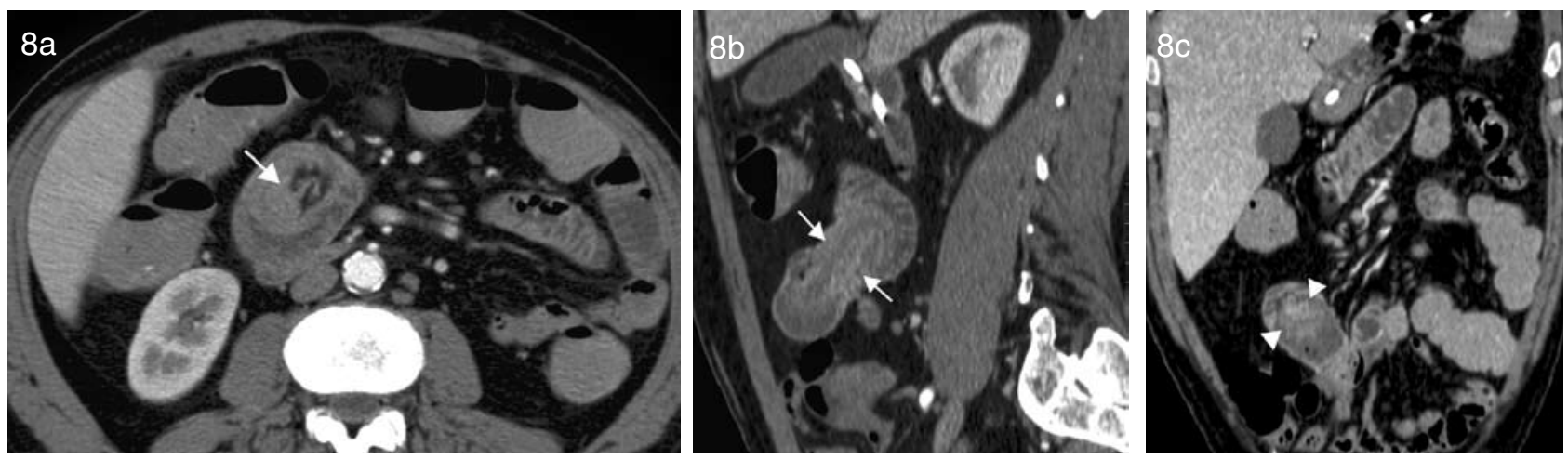

Figura 8. Hombre de 59 años con antecedentes de cáncer pulmonar. Imagen axial (a) y reconstrucción sagital (b) y coronal (c) de E-TC: intususcepción de asa de yeyuno proximal (flechas) secundaria a masa sólida intraluminal en el extremo distal (cabeza de flecha), hallazgos consistentes con localización secundaria de primario conocido. 

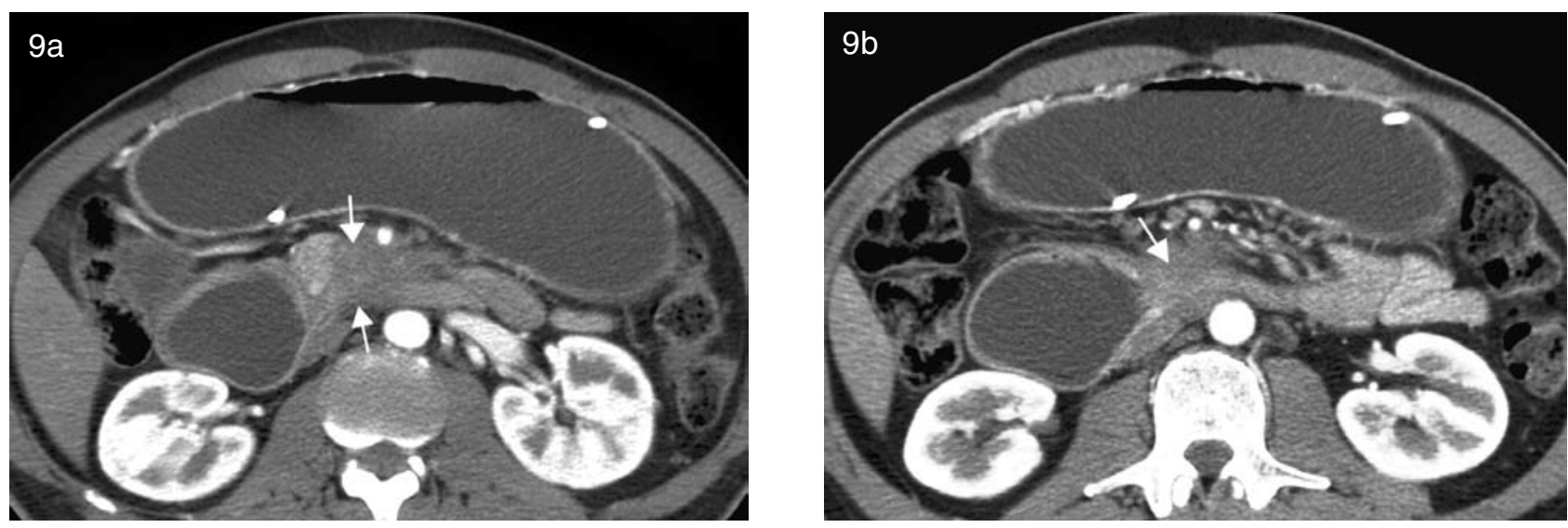

Figura 9. E-TC de hombre de 58 años con adenocarcinoma pancreático e infiltración duodenal secundaria. a,b) Imágenes axiales: masa hipovascular en el proceso uncinado del páncreas que infiltra la tercera porción del duodeno (flechas) y determina obstrucción del paso del agua, con dilatación gástrica y duodenal proximal e infiltración de arteria y vena mesentérica superior.

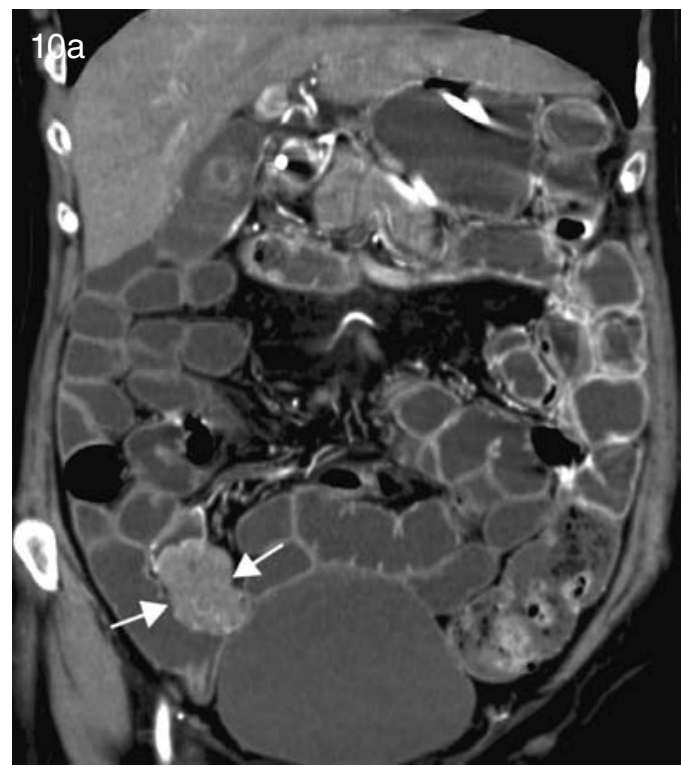

Figura 10. Mujer de 60 años con tumor estromal gastrointestinal benigno. Reconstrucción coronal (a) y sagital (b) de E-TC: adecuada distensión de asas de intestino delgado y masa sólida, exoentérica, en asa de ileon medio, que se impregna en forma homogénea con el contraste (flechas).

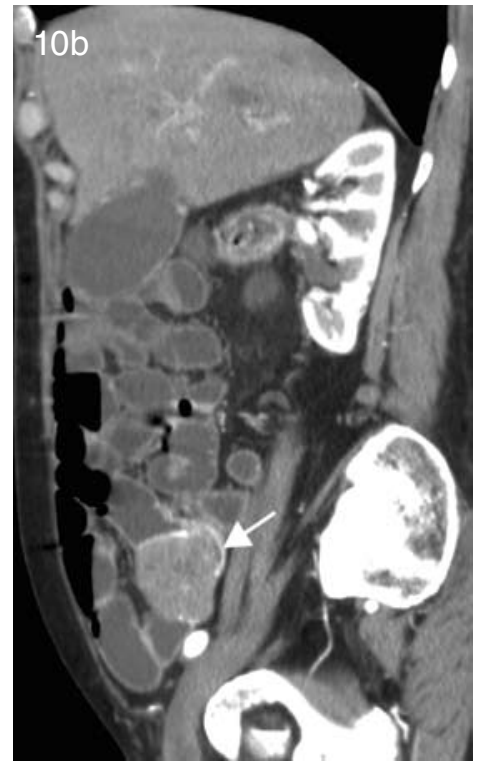

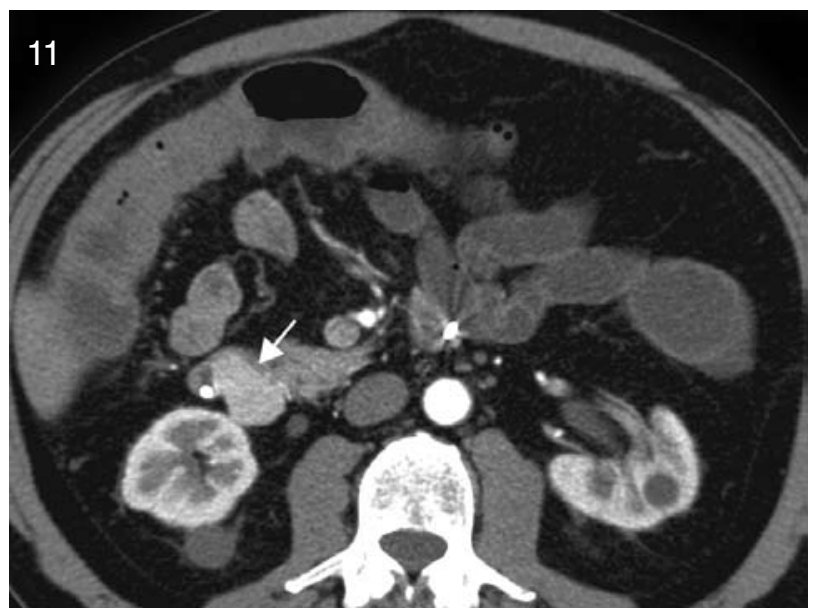

216
Figura 11. E-TC axial de hombre de 63 años: lesión submucosa en la segunda porción del duodeno con componente exofítico que contacta el riñón (flecha). Estudio histológico: tumor estromal gastrointestinal benigno. 


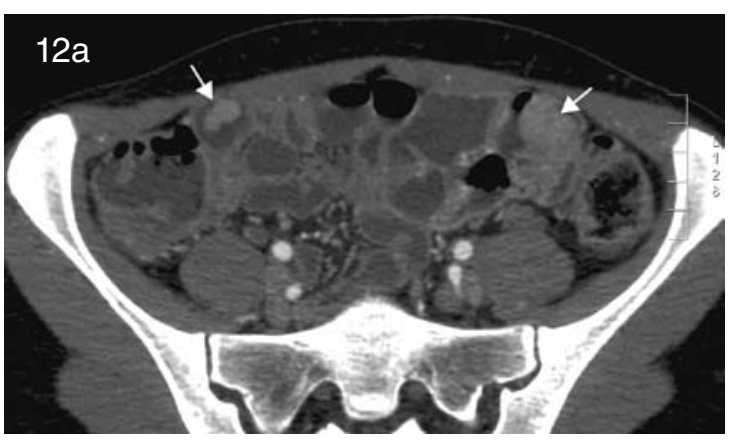

Figura 12. E-TC de una mujer de 22 años con síndrome de Peutz-Jeghers. Imagen axial (a) y reconstrucción coronal (b) muestran múltiples pólipos hamartomatosos en asas de yeyuno e ileon, que refuerzan intensamente con el uso de medio de contraste (flechas).
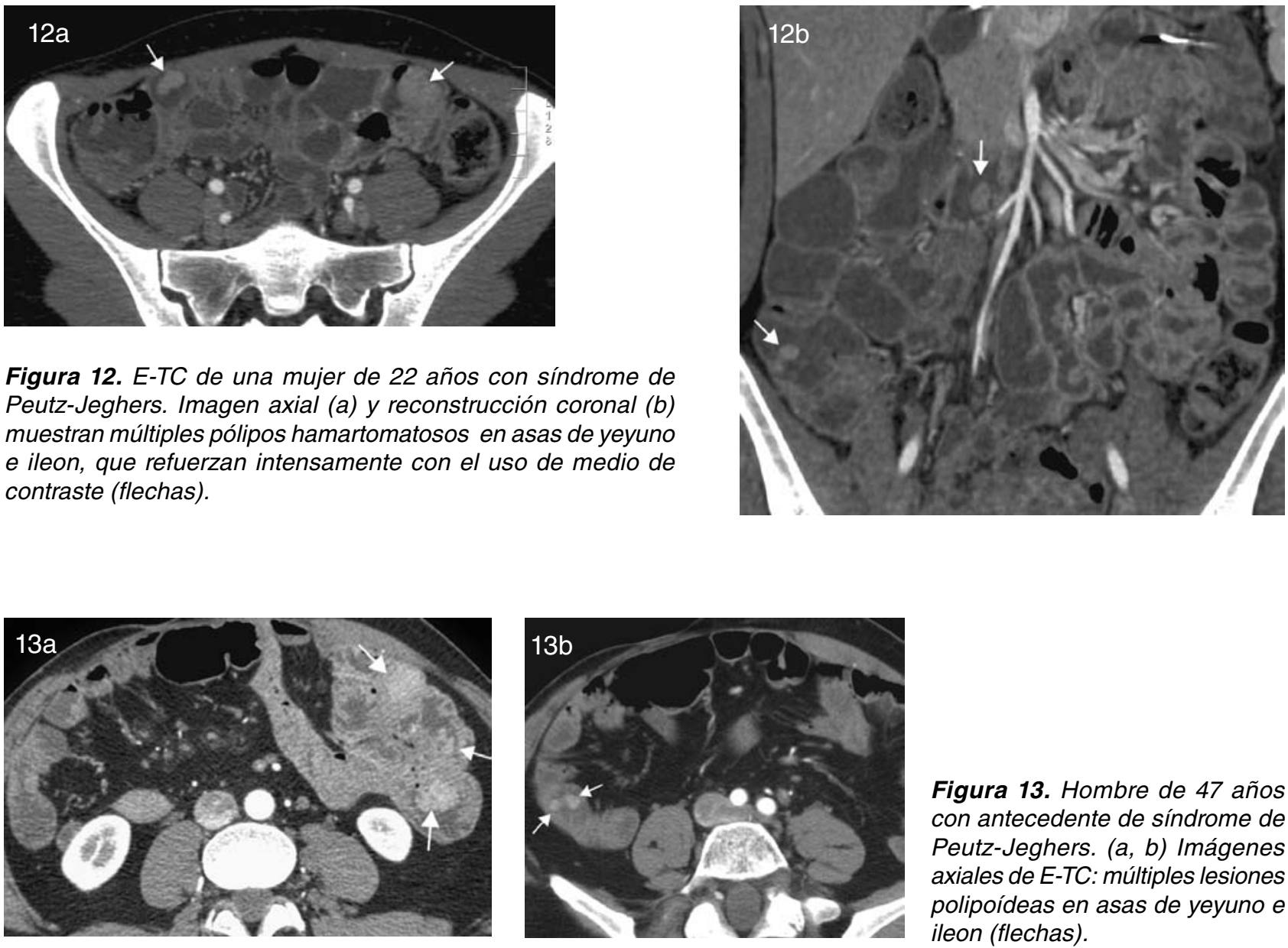

Figura 13. Hombre de 47 años con antecedente de síndrome de Peutz-Jeghers. (a, b) Imágenes axiales de E-TC: múltiples lesiones polipoídeas en asas de yeyuno e ileon (flechas).

\section{Discusión}

La E-TC es una técnica de imágenes que combina las ventajas de la enteroclisis convencional con las de la TC multicorte, permitiendo la detección de alteraciones intraluminales, intramurales y extramurales del ID. Hoy en día, la E-TC es ampliamente usada en la evaluación de diversas afecciones del ID que incluyen enfermedad inflamatoria intestinal, obstrucción intestinal parcial y patología tumoral, entre otras ${ }^{(11)}$.

Los medios de contraste enterales neutros utilizados en la técnica de E-TC incluyen agua, metilcelulosa y sulfato de bario diluido al $0,1 \%$, los que por su baja densidad permiten una adecuada diferenciación entre el lumen y la pared intestinal impregnada con medio de contraste endovenoso ${ }^{(10,11)}$. Nosotros preferimos el agua como agente enteral por su baja densidad, bajo costo y menor viscosidad, que permite utilizar sondas nasoenterales pequeñas y una mayor velocidad de infusión.

Desventajas de la técnica de E-TC son las molestias asociadas a la instalación de la sonda nasoenteral, mayor costo y tiempo del procedimiento y potencial riesgo de perforación intestinal y aspi- ración del medio de contraste enteral ${ }^{(10)}$. En nuestra experiencia, la E-TC es un procedimiento bien tolerado sin complicaciones reportadas.

En la serie de 600 E-TC realizadas en nuestra institución, este procedimiento permitió el diagnóstico de 22 tumores intestinales primarios y secundarios, que fueron confirmados histológicamente. En todos los pacientes analizados, el procedimiento fue fácil de realizar y bien tolerado.

En cuanto a la evaluación de patología tumoral de ID, hoy en día la E-TC se ha establecido como la modalidad de elección en diferentes centros, permitiendo en un mismo examen el diagnóstico y etapificación de tumores, detectando la extensión tumoral local, adenopatías y metástasis a distancia ${ }^{(11-17)}$. Pilleul et al, en un estudio prospectivo demostró que la E-TC tiene una sensibilidad y especificidad de $84,7 \%$ y $96,9 \%$ respectivamente en la detección de tumores de $\mathrm{ID}^{(15)}$. Además, la introducción de la TC multidetector con la posibilidad de realizar reconstrucciones multiplanares (2 y 3D) permite una visualización anatómica detallada de la ubicación y tamaño tumoral, información útil para los cirujanos en la planificación pre-operatoria.

Desventajas conocidas de la E-TC en la evaluación 
de tumores intestinales son hallazgos falsos positivos de pseudotumores, generalmente secundarios a pliegues intestinales o mucosa normal, lo que en general no constituye un problema diagnóstico si se logra una adecuada distensión de asas ${ }^{(15)}$.

Los diagnósticos obtenidos en nuestro estudio se asemejan a la distribución de tumores de intestino delgado reportada en las diferentes series, con un mayor porcentaje de tumores malignos $(81 \%)$ y de éstos los más frecuentes el adenocarcinoma y tumor carcinoide. En nuestra serie, aproximadamente un $60 \%$ de los tumores carcinoides se presentaron en forma multifocal, en comparación con un $30 \%$ en las distintas series reportadas.

De los tumores benignos encontrados, nuestro estudio tiene el sesgo de sólo incluir pacientes sintomáticos y con confirmación histológica, razón por la cual este grupo fue menos frecuente.

\section{Conclusión}

Esta serie corrobora el valor de la E-TC como técnica de imágenes de elección en la detección de patología de ID, en especial en la detección de tumores de intestino delgado por su capacidad de evaluar alteraciones intraluminales, murales y extraintestinales, permitiendo efectuar el diagnóstico y etapificación de los tumores de ID en un solo procedimiento.

\section{Bibliografía}

1. Zollinger RM. Primary Neoplasms of the small intestine. Am J Surg 1986; 151: 654- 658.

2. Gourtsoyiannis N, Mako E. Imaging of primary small intestinal tumours by enteroclysis and CT with pathological correlation. Eur Radiol 1997; 7: 625-642.

3. Matsuo S, Eto T, Tsunoda T, Kanematsu T, Shinozaki T. Small bowel tumors: an analysis of tumor-like lesions, benign and malignant neoplasms. Eur J Surg Oncol 1994; 20(1): 47-51.

4. Korman MU. Radiologic evaluation and staging of small intestine neoplasms. European Journal of Radiology
2002; 42: 193-205.

5. Dudiak KM, Johnson CD, Stephens DH. Primary Tumors of the Small Intestine: CT Evaluation. AJR 1989; 152: 995-998.

6. Halpert RD. Small Bowell. In: Halpert RD. Gastrointestinal Imaging The Requisites, 3d ed. Philadelphia, PA: Elsevier; 2006. pp.102-147.

7. Ramachandran I, Sinha R, Rajesh A, Verma R, Maglinte DD. Multidetector row CT of small bowel tumours. Clinical Radiology 2007; 62: 607-614.

8. O' Brien A. Enteroclisis por tomografía computada. Rev Chil Radiol. 2006; 12:70-75.

9. Gasparaitis AE, MacEneaney P. Enteroclysis and computed tomography enteroclysis. Gastroenterol Clin N Am 2002; 31: 715-730.

10. Maglinte DD, Sandrasegaran K, Lappas JC, Chiorean M. CT Enteroclysis. Radiology 2007; 245 (3): 661-671.

11. Schmidt S, Felley C, Meuwly J-V, Schnyder P, Denys A. CT enteroclysis: technique and clinical applications. Eur Radiol 2006; 16: 648-660.

12. Boudiaf M, Jaff A, Soyer P, Bouhnik Y, Hamzi L, Rymer R. Small-Bowel Diseases: Prospective Evaluation of Multi-Detector Row Helical CT Enteroclysis in 107 Consecutive Patients. Radiology 2004; 233: 338-344.

13. Sailer J, Zacherl J, Schima W. MDCT of small bowel tumours. Cancer Imaging 2007; 7: 224-33.

14. Romano S, De Lutio E, Rollandi GA, Romano L, Grassi R, Maglinte DD. Multidetector computed tomography enteroclysis (MDCT-E) with neutral enteral and IV contrast enhancement in tumor detection. Eur Radiol 2005; 15: 1178-1183.

15. Pilleul F, Penigaud M, Milot L, Saurin JC, Chayvialle JA, Valelle PJ . Possible Small-Bowel Neoplasms: Contrast-enhanced and Water-enhanced Multidetector CT Enteroclysis. Radiology 2006; 241 (3): 796-801.

16. Orjollet- Lecoanet $C$, Mènard $Y$, Martins $A$, Crombé -Ternamian A, Cotton F, Valelle PJ. CT Enteroclysis for detection of small bowel tumors. J Radiol 2000; 81: 618-627.

17. O’Brien A, Cruz JP, Berríos C, Melipillán Y, Butte JM, Alvarez M. Advances in radiography of the small intestine: computed tomography enteroclysis . Gastroenterol Hepatol 2006; 29(9): 528-533. 